Article

\title{
Living Radical Polymerization via Organic Superbase Catalysis
}

\section{Lin Lei, Miho Tanishima, Atsushi Goto * and Hironori Kaji *}

Institute for Chemical Research, Kyoto University, Uji, Kyoto 611-0011, Japan;

E-Mails: lei.lin.8m@kyoto-u.ac.jp (L.L.); tanishima.miho.83s@st.kyoto-u.ac.jp (M.T.)

* Authors to whom correspondence should be addressed; E-Mails: agoto@scl.kyoto-u.ac.jp (A.G.); kaji@scl.kyoto-u.ac.jp (H.K.); Tel.: +81-774-38-3151 (A.G.); Fax: +81-774-38-3148 (A.G.).

Received: 18 February 2014; in revised form: 8 March 2014 / Accepted: 12 March 2014 /

Published: 17 March 2014

\begin{abstract}
Organic superbases reacted with alkyl iodides $(\mathrm{R}-\mathrm{I})$ to reversibly generate the corresponding alkyl radicals $\left(\mathrm{R}^{\circ}\right)$. Via this reaction, organic superbases were utilized as new and highly efficient organic catalysts in living radical polymerization. The superbase catalysts included guanidines, aminophosphines and phosphazenes. Low-polydispersity polymers $\left(M_{\mathrm{w}} / M_{\mathrm{n}}=1.1-1.4\right)$ were obtained up to high conversions (e.g., 80\%) in reasonably short times $(3-12 \mathrm{~h})$ at mild temperatures $\left(60-80{ }^{\circ} \mathrm{C}\right)$ for methyl methacrylate, styrene and several functional methacrylates. The high polymerization rate and good monomer versatility are attractive features of these superbase catalysts.
\end{abstract}

Keywords: organic superbases; organic catalysts; living radical polymerization; reversible complexation mediated polymerization; radical chemistry; alkyl iodide

\section{Introduction}

Organic catalysts, in lieu of metal-based catalysts, have gained increasing attention, because many are environmentally benign, easy to handle and attractive alternatives in organic syntheses [1-3]. Metal-free catalytic processes are often practical and serve to broaden synthetic applications. Recent important studies in this field have involved the use of organic superbases, such as guanidines and phosphazenes, as catalysts. They exhibit high reactivity and high selectivity in many reactions, including fine organic transformations [4-7], such as asymmetric Michael addition, esterification and nitroaldol reactions, as well as fine polymer syntheses, such as ring-opening polymerization (ROP) [8] 
and group transfer polymerization (GTP) [9]. In all these cases, reactions have been either anionic or condensation reactions, rather than radical-based reactions.

Living radical polymerization (LRP) has become increasingly important in polymer chemistry, because it allows for the synthesis of well-defined polymers with narrow molecular weight distributions [10-20]. LRP is also called reversible deactivation radical polymerization (RDRP). Mechanistically, LRP is based on the reversible activation of a dormant species (Polymer-X) to a propagating radical (Polymer) (Scheme 1a). A sufficiently large number of activation-deactivation cycles are required for achieving low polydispersity (low dispersity) [21-24]. We recently developed new LRP systems using iodine as a capping agent and organic molecules as catalysts. We developed two mechanistically different systems, referred to as reversible chain transfer-catalyzed polymerization (RTCP) [25-31] and reversible coordination-mediated polymerization (RCMP) [31-35]. These polymerizations are metal-free systems. In this work, we focus on the latter system (RCMP). We previously employed amines, such as triethylamine (TEA) [32,34] and organic salts, such as tetrabutylammonium iodide (BNI) [35], as RCMP catalysts. RCMP involves reversible coordination of the catalyst to Polymer-I to generate Polymer and the catalyst-iodine complex (Scheme 1b).

Scheme 1. Reversible activation: (a) General scheme and (b) RCMP.

(a) Reversible activation (general scheme)

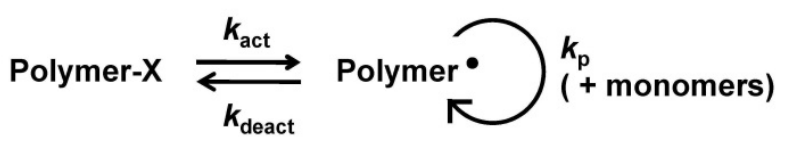

(b) RCMP

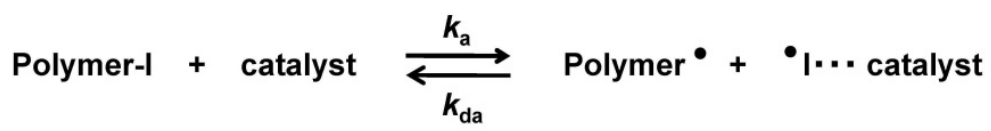

We are pursuing more reactive catalysts to widen the scope of RCMP. An important factor of active catalysts is their high ability to coordinate with iodine. As superbases are strong nucleophiles, they may strongly coordinate to iodine and work as active RCMP catalysts. Superbases have not been utilized as catalysts to induce radical reactions, as mentioned. An exploration of the use of superbases in a radical reaction is unique and would be interesting for both organic and polymer chemistry.

In this work, we demonstrate a unique reaction of alkyl iodides (R-I) with superbases to generate carbon-centered radicals $\left(\mathrm{R}^{\circ}\right)$ and the application of the superbases as highly active catalysts in RCMP. The superbases studied included a guanidine (TMG), an aminophosphine (TiBP) and phosphazenes $\left(\mathrm{t}-\mathrm{Bu}-\mathrm{P}_{4}\right.$ and $\left.\mathrm{t}-\mathrm{Bu}-\mathrm{P}_{2}\right)$ depicted in Figure 1 . We studied the polymerizations of methyl methacrylate (MMA), styrene (St) and three functional methacrylates at $60-80{ }^{\circ} \mathrm{C}$. 
Figure 1. Structures of alkyl iodides and catalysts used in this work.

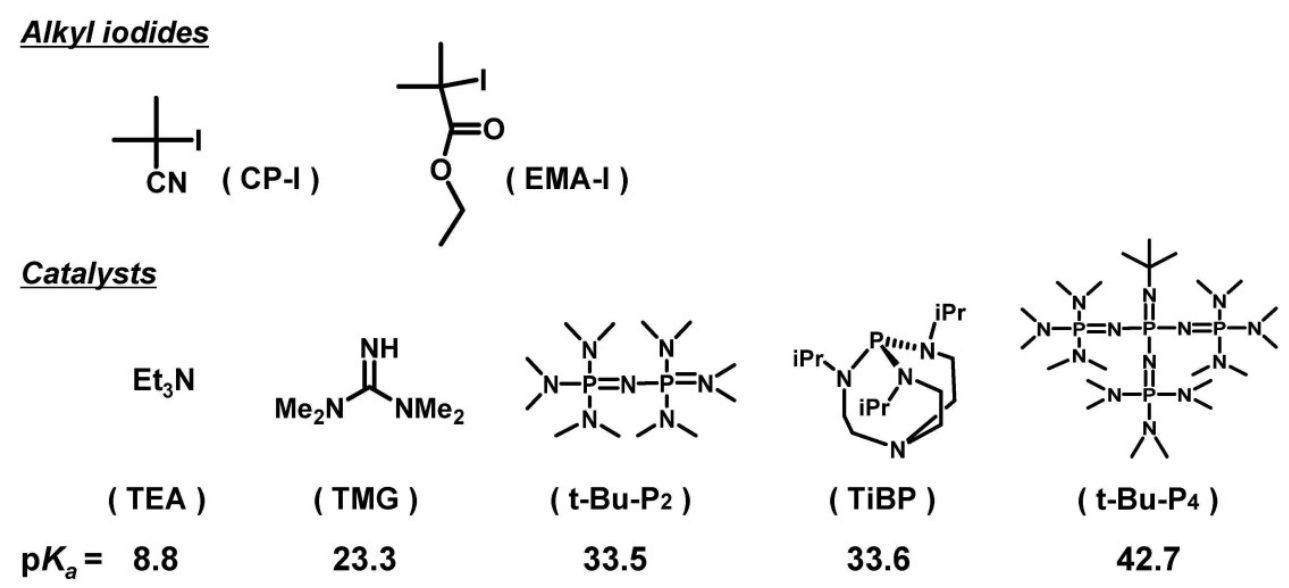

\section{Experimental Section}

\subsection{Materials}

MMA (99\%, Nacalai Tesque, Kyoto, Japan), St (99\%, Nacalai), benzyl methacrylate (BzMA) (96\%, Aldrich, St. Louis, MO, USA), glycidyl methacrylate (GMA) (97\%, Aldrich), and poly(ethylene glycol) methyl ether methacrylate (PEGMA) (average molecular weight $=300)(98 \%$, Aldrich) were purified on an alumina column. 2-Cyanopropyl iodide (CP-I) (99\%, Tokyo Chemical Industry (TCI), Tokyo, Japan (contract service)), $\mathrm{I}_{2}$ (98\%, Wako Pure Chemical, Osaka, Japan), TMG (99\%, Wako), TiBP (97\%, Aldrich), t-Bu- $\mathrm{P}_{2}$ (2.0 M in THF, Aldrich), t-Bu- $\mathrm{P}_{4}$ (1.0 M in hexane, Aldrich), TEA (99\%, Wako), 2,2"-azobis(2,4-dimethyl valeronitrile) (V65) (95\%, Wako), 2,2"-azobis(4-methoxy-2,4dimethyl valeronitrile) (V70) (95\%, Wako), (2,2,6,6-tetramethylpiperidine-1-oxyl (TEMPO) (99\%, Aldrich) and toluene (99.5\%, Nacalai) were used as received. Ethyl 2-iodoisobutyrate (EMA-I) (99\%) was provided through the courtesy of Godo Shigen Sangyo Co., LTD, Chiba, Japan.

\subsection{GPC Measurements}

Gel permeation chromatography (GPC) analysis was performed on a Shodex GPC-101 liquid chromatograph (Tokyo, Japan) equipped with two Shodex KF-804L mixed gel columns $(300 \mathrm{~mm} \times 8.0 \mathrm{~mm}$; bead size $=7 \mu \mathrm{m}$; pore size $=20-200 \AA)$. The eluent was tetrahydrofuran $(\mathrm{THF})$ or dimethyl formamide (DMF) with a flow rate of $0.8 \mathrm{~mL} \cdot \mathrm{min}^{-1}\left(40{ }^{\circ} \mathrm{C}\right)$. Sample detection and quantification were conducted using a Shodex RI-101 differential refractometer calibrated with solutions of known polymer concentrations. The monomer conversion was determined from the GPC peak area. The column system was calibrated using poly(methyl methacrylate) and polystyrene standards. For the polymerizations of BzMA, GMA and PEGMA, the samples were also detected using a Wyatt Technology DAWN EOS multiangle laser light-scattering (MALLS) detector (Santa Barbara, CA, USA) equipped with a Ga-As laser $(\lambda=690 \mathrm{~nm})$. The refractive index increment $d_{n} / d_{c}$ was determined to be for $0.155 \mathrm{~mL} \cdot \mathrm{g}^{-1}$ for BzMA (in THF), $0.0962 \mathrm{~mL} \cdot \mathrm{g}^{-1}$ for GMA (in THF) and $0.054 \mathrm{~mL} \cdot \mathrm{g}^{-1}$ for PEGMA (in DMF), using a Wyatt Technology OPTILAB DSP differential refractometer $(\lambda=690 \mathrm{~nm})$. 


\subsection{NMR Measurement}

The NMR spectra were acquired on a Bruker (Karlsruhe, Germany) Avance III (800 MHz) at ambient temperature; ${ }^{1} \mathrm{H}$ : spectral width $24038.461 \mathrm{~Hz}$, acquisition time $1.9923 \mathrm{~s}$ and pulse delay $5.000 \mathrm{~s}$.

\subsection{Radical Trap Experiments}

A mixture of toluene- $d_{8}(2.0 \mathrm{~mL}), \mathrm{CP}-\mathrm{I}(5 \mathrm{mM})$, a catalyst $(80 \mathrm{mM})$ and TEMPO $(80 \mathrm{mM})$ was heated in a Schlenk flask at $70{ }^{\circ} \mathrm{C}$ for $12 \mathrm{~h}$ under an argon atmosphere with magnetic stirring and then quenched to room temperature. The mixtures before and after the heat treatment were analyzed by ${ }^{1} \mathrm{H} N \mathrm{NR}$.

\subsection{Polymerizations}

In a typical run, a Schlenk flask containing a mixture of MMA $(3 \mathrm{~mL}), \mathrm{CP}-\mathrm{I}$ and a catalyst was heated at $60{ }^{\circ} \mathrm{C}$ under an argon atmosphere with magnetic stirring. After a prescribed time $t$, an aliquot $(0.1 \mathrm{~mL})$ of the solution was taken out by a syringe, quenched to room temperature, diluted by THF or DMF to a known concentration and analyzed by GPC.

\section{Results and Discussion}

\subsection{Experimental Prooffor Generation of $R^{\bullet}$ from $R-I$ with Superbase Catalysts}

A radical trap experiment was performed to demonstrate the generation of a carbon-centered radical $\mathrm{R}^{\circ}$ from R-I with a superbase catalyst [34-38]. We used CP-I (Figure 1) as R-I and TMG and TiBP as catalysts. In each radical trap trial, we heated $\mathrm{CP}-\mathrm{I}(5 \mathrm{mM})$, a catalyst $(80 \mathrm{mM})$ and the radical trap TEMPO $(80 \mathrm{mM})$ at $70{ }^{\circ} \mathrm{C}$ in toluene- $d_{8}$. If $\mathrm{CP}-\mathrm{I}$ reacted with a catalyst, the generated radical $\mathrm{CP}^{\circ}$ would be trapped by TEMPO, thereby yielding CP-TEMPO. Figure 2 shows the ${ }^{1} \mathrm{H}$ NMR spectra at time zero and at $12 \mathrm{~h}$ for TMG. At $12 \mathrm{~h}$, new signals appeared and matched those of pure CP-TEMPO that was independently prepared. The extent of reaction of CP-I to CP-TEMPO was virtually $100 \%$ for both TMG and TiBP. The results clearly demonstrate the generation of $\mathrm{R}^{\circ}$ from R-I with superbase catalysts and at the same time, negligible generation of the corresponding carbon-centered anion $\mathrm{R}^{-}$.

$\mathrm{CP}-\mathrm{I}$ can be used as an initiating dormant species in RCMP. The quantitative generation of an alkyl radical from $\mathrm{CP}-\mathrm{I}$ with TMG and TiBP suggests that TMG and TiBP can be effective catalysts in RCMP. Thus, we attempted to utilize superbases as catalysts for RCMP, as described in subsequent sections. 
Figure 2. ${ }^{1} \mathrm{H}$ NMR spectra (in the range of $0.8-2.8 \mathrm{ppm}$ ) of the solution of $\mathrm{CP}-\mathrm{I}(5 \mathrm{mM})$, TMG $(80 \mathrm{mM})$ and TEMPO $(80 \mathrm{mM})$ in toluene- $d_{8}$ heated at $70{ }^{\circ} \mathrm{C}$ for 0 and $12 \mathrm{~h}$.

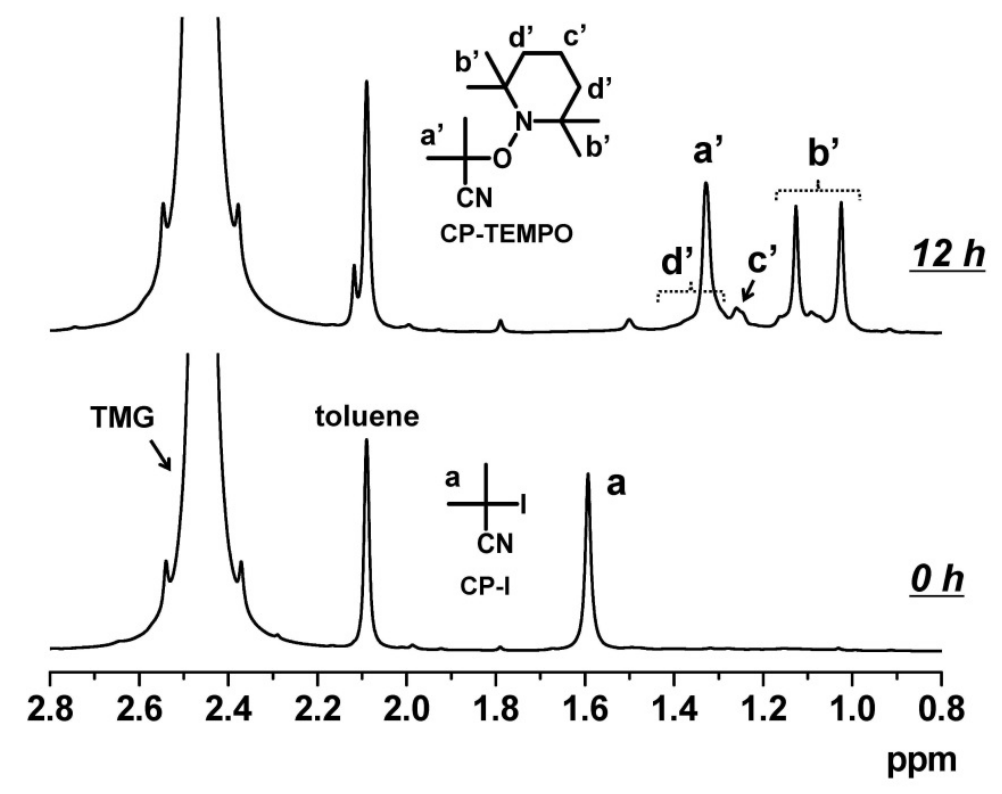

\subsection{Polymerization of MMA with TiBP}

We carried out the polymerizations of MMA using either TiBP as a superbase catalyst or BNI as a previously studied organic salt catalyst and compared the polymerization results. Figure 3 shows the polymerizations of MMA $(8 \mathrm{M})$ with $\mathrm{CP}-\mathrm{I}(80 \mathrm{mM})$ as an initiating dormant species and a catalyst $(80 \mathrm{mM})$ at $60{ }^{\circ} \mathrm{C}$. TiBP (open circles) led to $70 \%$ monomer conversion after approximately $2 \mathrm{~h}$, whereas BNI (squares) led to the same conversion after approximately $7 \mathrm{~h}$, clearly displaying a much larger polymerization rate $R_{\mathrm{p}}$ in the TiBP system. However, in the TiBP system (open circles), the number-average molecular weight $M_{\mathrm{n}}$ deviated from the theoretical value $M_{\mathrm{n} \text {,theo }}$ and the polydispersity index (PDI) ( $=M_{\mathrm{w}} / M_{\mathrm{n}}$, where $M_{\mathrm{w}}$ is the weight-average molecular weight) was larger than 2.0. This results from an insufficient accumulation of deactivator $\left(\mathrm{I}_{2} /\right.$ catalyst complex $)$ in the early stage of polymerization, when many monomers added to Polymer. Thus, we introduced molecular iodine $\left(\mathrm{I}_{2}\right)$ as a stating compound, which yields an $\mathrm{I}_{2} /$ TiBP deactivator complex. The addition of $\mathrm{I}_{2}(20 \mathrm{mM})$ (filled circles) led to good agreement of $M_{\mathrm{n}}$ with $M_{\mathrm{n} \text {,theo }}$ and a small PDI $(=1.3)$ from an early stage of polymerization. The PDI remained small $(=1.25)$ even at a high conversion (94\%), suggesting insignificant side reactions. The $R_{\mathrm{p}}$ with $\mathrm{I}_{2}$ was slightly lower than that without it (as expected from the equilibrium in Scheme 1b) but was still approximately three times higher than that in the BNI system. These results clearly demonstrate the high reactivity and usefulness of TiBP as a catalyst in RCMP. The results are summarized in Table 1 (entries 1-3). 
Figure 3. Plots of (a) $\ln \left([\mathrm{M}]_{0} /[\mathrm{M}]\right) v s$. $t$ and (b) $M_{\mathrm{n}}$ and $M_{\mathrm{w}} / M_{\mathrm{n}} v s$. conversion for the MMA/CP-I/catalyst systems (in bulk) $\left(60^{\circ} \mathrm{C}\right)$ (entries $1-3$ in Table 1): $[\mathrm{MMA}]_{0}=8 \mathrm{M}$; $[\mathrm{CP}-\mathrm{I}]_{0}=80 \mathrm{mM}$. The concentrations of catalyst and $\mathrm{I}_{2}$ and the symbols are as indicated in the figure.
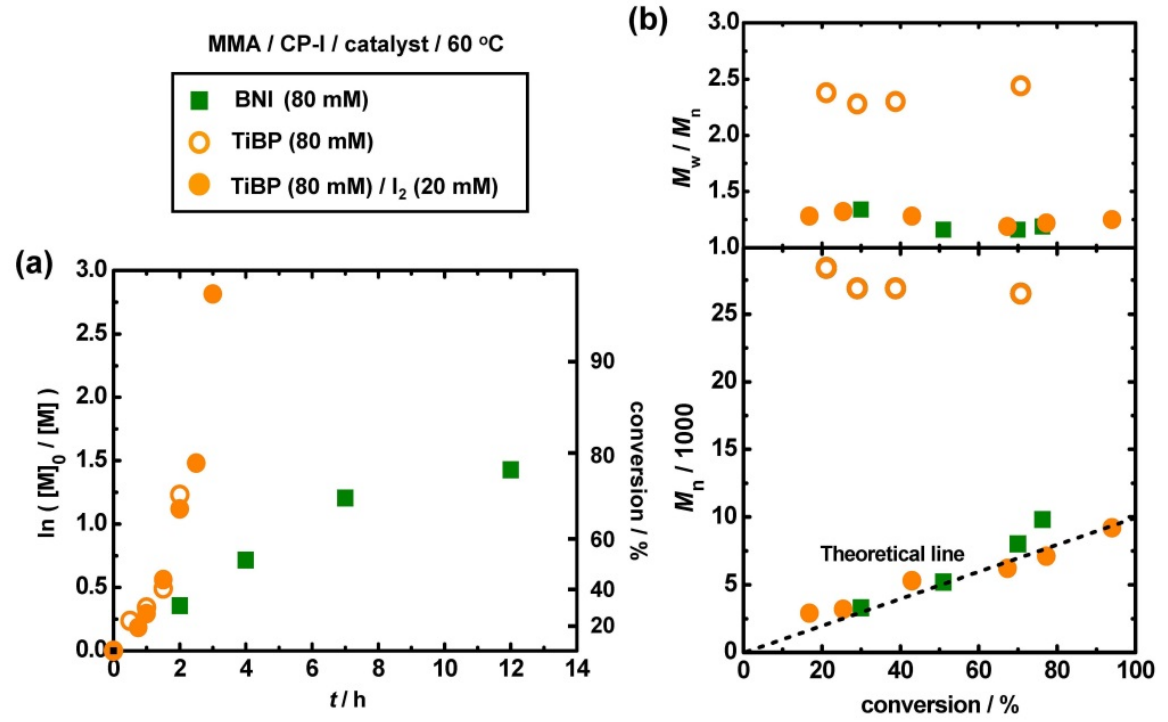

Table 1. Polymerizations of methyl methacrylate (MMA).

\begin{tabular}{|c|c|c|c|c|c|c|c|c|c|}
\hline Entry & $\begin{array}{l}\text { Target } \\
\text { DP }\end{array}$ & Catalyst & $\begin{array}{c}{[\mathrm{CP}-\mathrm{I}]_{0} /[\text { catalyst }]_{0} /\left[\mathrm{I}_{2}\right]_{0}} \\
(\mathrm{mM})\end{array}$ & Solvent & $t$ (h) & $T\left({ }^{\circ} \mathbf{C}\right)$ & $\begin{array}{l}\text { Conv } \\
(\%)\end{array}$ & $M_{\mathrm{n}}\left(M_{\mathrm{n}, \text { theo }}\right)$ & PDI \\
\hline 1 & 100 & BNI & $80 / 80$ & bulk & 7 & 60 & 70 & $8,000(7,000)$ & 1.16 \\
\hline 2 & 100 & TiBP & $80 / 80$ & bulk & 2 & 60 & 71 & $27,000(7,100)$ & 2.44 \\
\hline 3 & 100 & TiBP & $80 / 80 / 20$ & bulk & 3 & 60 & 94 & $9,200(9,400)$ & 1.25 \\
\hline 4 & 100 & TiBP & $80 / 40 / 5$ & bulk & 4 & 60 & 74 & $10,000(7,400)$ & 1.29 \\
\hline 5 & 100 & TMG & $80 / 40 / 5$ & bulk & 12 & 60 & 44 & $6,000(4,400)$ & 1.13 \\
\hline 6 & 100 & TMG & $80 / 80 / 0$ & bulk & 10 & 60 & 63 & $9,000(6,300)$ & 1.33 \\
\hline 7 & 100 & $\mathrm{t}-\mathrm{Bu}-\mathrm{P}_{2}$ & $80 / 40 / 5$ & bulk & 12 & 60 & 76 & $17,000(7,600)$ & 1.23 \\
\hline 8 & 100 & $\mathrm{t}-\mathrm{Bu}-\mathrm{P}_{2}$ & $80 / 40 / 0$ & bulk & 6 & 60 & 64 & $14,000(6,400)$ & 1.16 \\
\hline 9 & 100 & $\mathrm{t}-\mathrm{Bu}-\mathrm{P}_{4}$ & $80 / 40 / 5$ & bulk & 8 & 60 & 82 & $14,000(8,200)$ & 1.33 \\
\hline 10 & 100 & $\mathrm{t}-\mathrm{Bu}-\mathrm{P}_{4}$ & $80 / 40 / 0$ & bulk & 6 & 60 & 65 & $14,000(7,000)$ & 1.40 \\
\hline 11 & 100 & TEA & $80 / 40 / 5$ & bulk & 10 & 60 & 45 & $6,300(4,500)$ & 1.29 \\
\hline 12 & 400 & TiBP & $20 / 40 / 10$ & Toluene $^{a}$ & 24 & 60 & 91 & $45,000(36,000)$ & 1.45 \\
\hline 13 & 400 & TiBP & $20 / 80 / 25$ & Toluene $^{a}$ & 14 & 60 & 82 & $38,000(33,000)$ & 1.20 \\
\hline
\end{tabular}

${ }^{a}$ Diluted in $25 \mathrm{wt} \%$ toluene (solution polymerization).

\subsection{Polymerization from EMA-I}

To further probe the high reactivity of TiBP, we studied the polymerizations of MMA with EMA-I (Figure 1) as an initiating dormant species. As the bond strength of EMA-I is higher than that of $\mathrm{CP}-\mathrm{I}$, highly reactive catalysts are required for its initiation. Figure 4 shows the polymerizations of MMA with EMA-I using TiBP and BNI catalysts at $70{ }^{\circ} \mathrm{C}$. TiBP afforded good polymerization control, whereas BNI led to a large deviation in $M_{\mathrm{n}}$ and broad polydispersity because of the slow initiation of EMA-I. This result clearly demonstrates that TiBP has a higher activation ability than BNI. 
Figure 4. Plots of (a) $\ln \left([\mathrm{M}]_{0} /[\mathrm{M}]\right) v s$. $t$ and (b) $M_{\mathrm{n}}$ and $M_{\mathrm{w}} / M_{\mathrm{n}} v s$. conversion for the MMA/R-I/catalyst systems (in bulk) $\left(70{ }^{\circ} \mathrm{C}\right):[\mathrm{MMA}]_{0}=8 \mathrm{M}$; [EMA-I $]_{0}=80 \mathrm{mM}$; $[\text { catalyst }]_{0}=80 \mathrm{mM}$. The catalysts and the symbols are as indicated in the figure. For the TiBP systems, $\mathrm{I}_{2}(30 \mathrm{mM})$ was added.

MMA / EMA-I / catalyst $/ 70^{\circ} \mathrm{C}$

EMA-I / TiBP $(80 \mathrm{mM}) / \mathrm{I}_{2}(30 \mathrm{mM})$ EMA-I / BNI (80 mM)

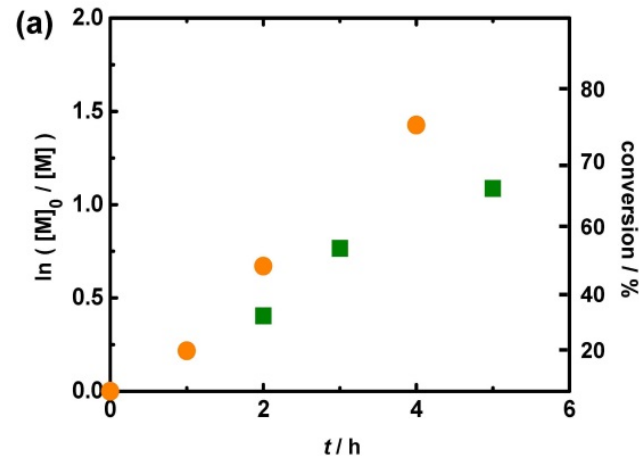

(b)

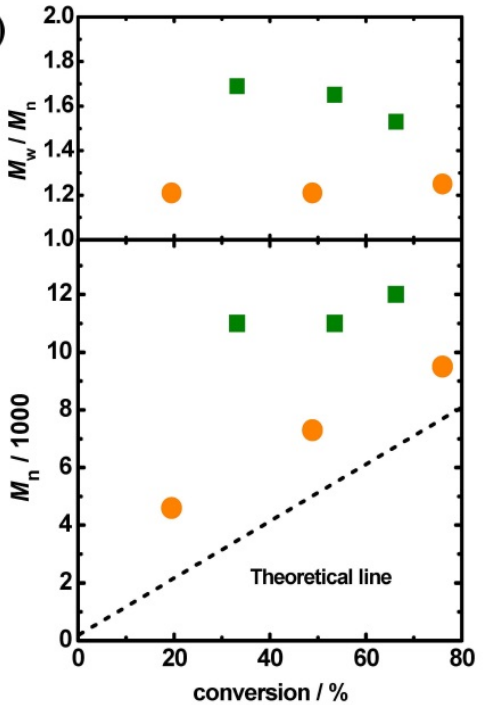

\subsection{Other Superbase Catalysts}

In addition to TiBP, we examined TMG, t-Bu- $\mathrm{P}_{4}$ and $\mathrm{t}-\mathrm{Bu}-\mathrm{P}_{2}$ as superbase catalysts in RCMP to probe the relationship between basicity and catalytic reactivity in RCMP. We also examined a previously studied weak base catalyst, TEA, for comparison. Among these bases, $\mathrm{p} K_{a}$ increases in the order of TEA $\left(\mathrm{p} K_{a}=10.8\right)<\mathrm{TMG}(23.3)<\mathrm{t}-\mathrm{Bu}-\mathrm{P}_{2}(33.5)<\mathrm{TiBP}(33.6)<\mathrm{t}-\mathrm{Bu}_{4} \mathrm{P}_{4}$ (42.7) (Figure 1) [39]. Figure 5 and Table 1 (entries 4, 5, 7, 9 and 11) compare the polymerizations of MMA with these catalysts at fixed concentrations of CP-I $(80 \mathrm{mM})$, catalyst $(40 \mathrm{mM})$ and $\mathrm{I}_{2}(5 \mathrm{mM})$ at $60{ }^{\circ} \mathrm{C}$. Low-polydispersity polymers (PDI $=1.1-1.4$ ) were obtained up to high conversions in all cases. The $R_{\mathrm{p}}$ was significantly different among the catalysts. As a whole, the higher $\mathrm{p} K_{a}$ systems $\left(\mathrm{t}-\mathrm{Bu}-\mathrm{P}_{4}, \mathrm{TiBP}\right.$ and t-Bu- $\mathrm{P}_{2}$ ) afforded larger $R_{\mathrm{p}}$ than the lower $\mathrm{p} K_{a}$ systems (TMG and TEA). These results clearly demonstrate that higher basicity generally tends to produce higher catalytic activity, as expected. On the other hand, TiBP and t-Bu- $\mathrm{P}_{2}$ exhibited significantly different $R_{\mathrm{p}}$ despite their similar basicities. This result suggests that the ability of the catalyst to coordinate to iodine depends not only on basicity but also on other factors such as steric hindrance. In an anionic reaction (the coordination to silicon), Kakuchi and Satoh et al. also observed a similar general tendency as well as the contribution of other factors [9].

TMG, t-Bu- $\mathrm{P}_{4}$ and $\mathrm{t}-\mathrm{Bu}-\mathrm{P}_{2}$ afforded low polydispersity even without the addition of $\mathrm{I}_{2}$ (Table 1 (entries 6, 8 and 10)) in contrast to TiBP. In the $\mathrm{t}-\mathrm{Bu}-\mathrm{P}_{4}$ and $\mathrm{t}-\mathrm{Bu}-\mathrm{P}_{2}$ systems, $M_{\mathrm{n}}$ linearly increased with conversion but was approximately twice as large as $M_{\mathrm{n} \text {,theo }}$ for reasons that remain unclear.

The obtained results (Figures $2-5$ and Table 1 (entries 1-11)) clearly demonstrate the high catalytic reactivities of the superbases. The small PDIs achievable up to high conversions in reasonably short times (3-12 h) are attractive features of these superbase catalysts. 
Figure 5. Plots of (a) $\ln \left([\mathrm{M}]_{0} /[\mathrm{M}]\right) v s$. $t$ and (b) $M_{\mathrm{n}}$ and $M_{\mathrm{w}} / M_{\mathrm{n}} v s$. conversion for the $\mathrm{MMA} / \mathrm{CP}-\mathrm{I} /$ catalyst systems (in bulk) $\left(60^{\circ} \mathrm{C}\right)$ (entries 4, 5, 7, 9 and 11 in Table 1): $[\mathrm{MMA}]_{0}=8 \mathrm{M} ;[\mathrm{CP}-\mathrm{I}]_{0}=80 \mathrm{mM} ;[\text { catalyst }]_{0}=40 \mathrm{mM} ;\left[\mathrm{I}_{2}\right]_{0}=5 \mathrm{mM}$. The catalysts and the symbols are as indicated in the figure.
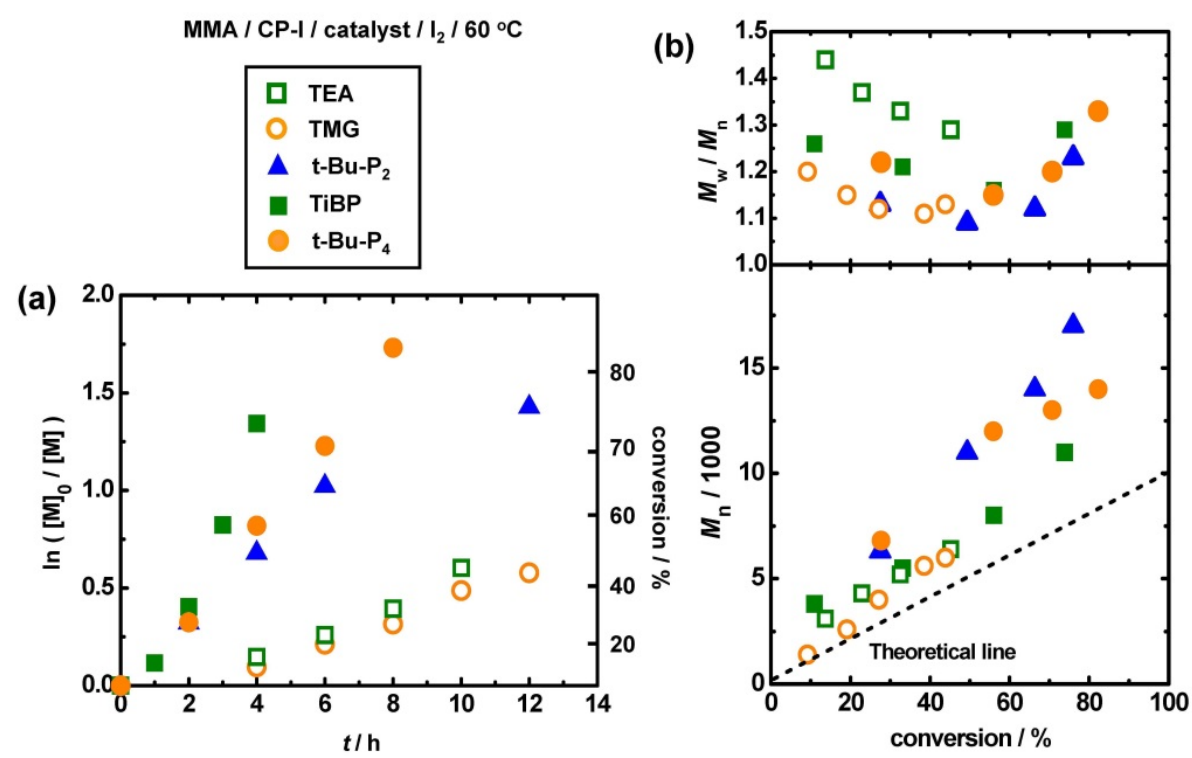

\subsection{Higher Molecular Weights Polymers and Some Functional Methacrylates}

Higher molecular weight polymers were also prepared in the MMA polymerizations. TiBP was used as a catalyst to maintain a sufficiently large $R_{\mathrm{p}}$. Figure 6 and Table 1 (entries 12 and 13) show examples at a targeted degree of polymerization of 400 at $100 \%$ conversion. We obtained low-polydispersity (PDI $=1.1-1.4$ ) polymers up to a molecular weight of 45,000 in these cases. Table 2 shows the results of the polymerizations of functional methacrylates with benzyl (BzMA), epoxy (GMA) and poly(ethyleneglycol) (PEGMA) groups (entries 3-8) using TiBP and TMG. Low polydispersity polymers were obtained up to high conversion $(65 \%-100 \%)$, demonstrating good compatibility with these functional groups.

Table 2. Polymerizations of Functional Methacrylates (in Bulk).

\begin{tabular}{cccccccccc}
\hline Entry & Monomer & $\begin{array}{c}\text { Target } \\
\text { DP }\end{array}$ & Catalyst & $\begin{array}{c}{\left[\mathbf{C P}-\mathbf{I}_{\mathbf{0}} /[\text { catalyst }]_{\mathbf{0}} /\left[\mathbf{I}_{\mathbf{2}}\right]_{\mathbf{0}}\right.} \\
(\mathbf{m M})\end{array}$ & $\boldsymbol{T}\left(\mathbf{(}^{\mathbf{0}} \mathbf{C}\right)$ & $\boldsymbol{t}(\mathbf{h})$ & $\begin{array}{c}\text { Conv } \\
(\mathbf{\%})\end{array}$ & $\boldsymbol{M}_{\mathbf{n}}\left(\boldsymbol{M}_{\mathbf{n}, \text { heo }}\right)$ & PDI \\
\hline 1 & BzMA & 100 & TiBP & $80 / 40 / 10$ & 60 & 8 & 73 & $12,000(13,000)$ & 1.39 \\
2 & BzMA & 100 & TMG & $80 / 80 / 2$ & 60 & 30 & 67 & $15,000(12,000)$ & 1.37 \\
3 & GMA $^{a}$ & 100 & TiBP & $80 / 10 / 7$ & 60 & 9 & 72 & $7,500(10,000)$ & 1.27 \\
4 & PEGMA $^{a}$ & 100 & TiBP & $80 / 40 / 10$ & 60 & 6 & 100 & $19,000(30,000)$ & 1.36 \\
5 & PEGMA $^{a}$ & 100 & TMG & $80 / 40 / 2$ & 60 & 6 & 100 & $16,000(30,000)$ & 1.40 \\
\hline
\end{tabular}

${ }^{a}$ Molecular weight of monomer $=300$. 
Figure 6. Plots of (a) $\ln \left([\mathrm{M}]_{0} /[\mathrm{M}]\right) v s$. $t$ and (b) $M_{\mathrm{n}}$ and $M_{\mathrm{w}} / M_{\mathrm{n}} v s$. conversion for the $\mathrm{MMA} / \mathrm{CP}-\mathrm{I} / \mathrm{TiBP} / \mathrm{I}_{2}$ systems $\left(60{ }^{\circ} \mathrm{C}\right)$ (entries 12 and 13 in Table 1): $[\mathrm{MMA}]_{0}=8 \mathrm{M}$; $[\mathrm{CP}-\mathrm{I}]_{0}=20 \mathrm{mM}$. The polymerizations were carried out in $25 \mathrm{wt} \%$ toluene. The concentrations of TiBP and $\mathrm{I}_{2}$ and the symbols are as indicated in the figure.
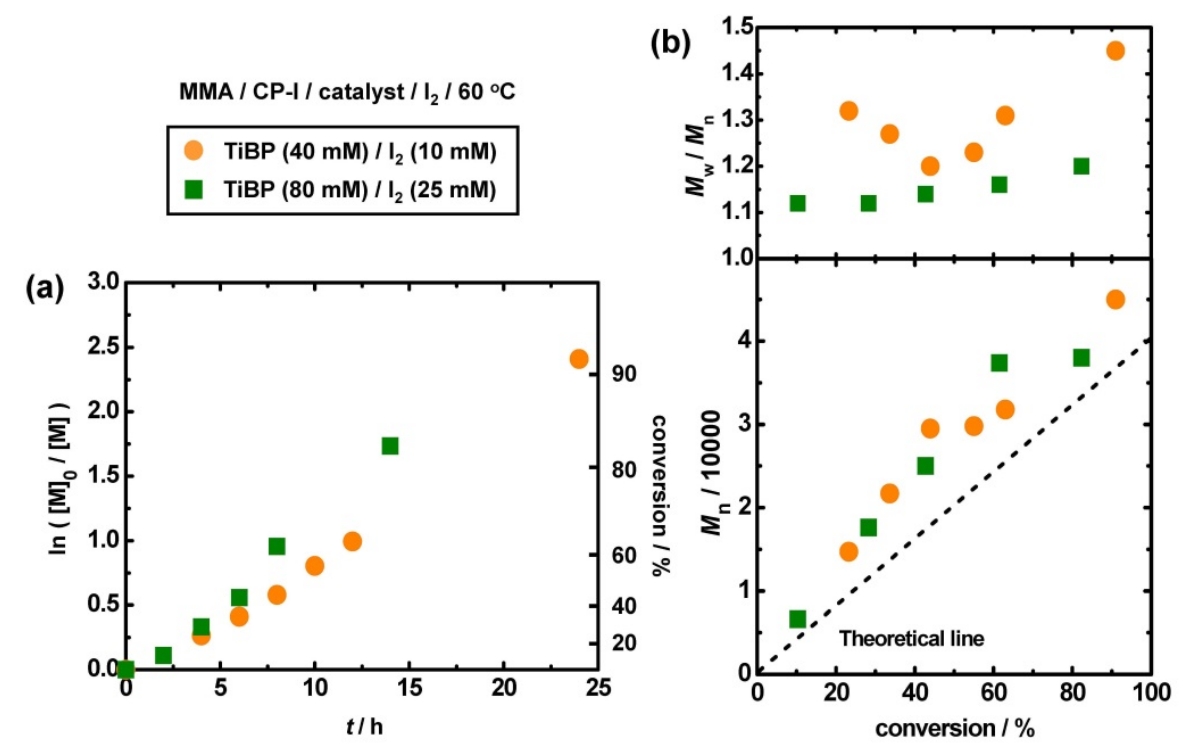

\subsection{Use of Alkyl iodide Formed in Situ}

In the above-mentioned systems, we employed a preformed alkyl iodide $\mathrm{R}-\mathrm{I}$ as the starting dormant species. Instead of a preformed $\mathrm{R}-\mathrm{I}$, molecular iodine $\left(\mathrm{I}_{2}\right)$ and an azo compound $(\mathrm{R}-\mathrm{N}=\mathrm{N}-\mathrm{R})$ can be used as starting compounds and for the polymerization, an R-I formed in situ can be used. This method ( $\left.\mathrm{I}_{2} / \mathrm{azo}\right)$ was originally invented by Lacroix-Desmazes et al. for iodide-mediated LRP [40,41]. We previously showed that this method is effective for RTCP [26,27,30,31] and RCMP [33,35].

Figure 7 (circles) and Table 3 (entry 1) show the polymerization of MMA (8 M) with $\mathrm{I}_{2}(40 \mathrm{mM})$, $\mathrm{V} 70(40 \mathrm{mM})$ and $\mathrm{TiBP}(20 \mathrm{mM})$ at $60{ }^{\circ} \mathrm{C}$. $\mathrm{V} 70$ affords the alkyl radical $\mathrm{R}^{\circ}$ and $\mathrm{R}^{\circ}$ reacts with $\mathrm{I}_{2}$ to yield R-I. Virtually no polymerization occurred after $0.5 \mathrm{~h}$, during which time $\mathrm{R}^{\bullet}$ had predominantly reacted with $\mathrm{I}_{2}$ (rather than monomer) and $\mathrm{R}-\mathrm{I}$ had accumulated. Because the efficiency of V70 to produce free $\mathrm{R}^{\circ}$ is approximately $0.6-0.7,40 \mathrm{mM}$ of $\mathrm{V} 70$ can yield about $60 \mathrm{mM}$ of free $\mathrm{R}^{\circ}$ and hence about $60 \mathrm{mM}$ (theoretical amount) of R-I. After this period, the polymerization smoothly proceeded (Figure 7). The $M_{\mathrm{n}}$ well agreed with $M_{\mathrm{n} \text {,theo }}$ and PDI remained small (approximately 1.1) throughout the polymerization.

This method was also successfully applied to higher targeted degrees of polymerization (DPs) (= 270 and 530) in the MMA/TiBP system (Figure 7 (squares and triangles) and Table 3 (entries 2 and 3)). Low polydispersity was achieved up to a molecular weight of 52,000 in this studied case. This method was also effective for another monomer, $\mathrm{St}$ and other catalysts (TiBP, TMG and t-Bu- $\mathrm{P}_{4}$ ) (Table 3 (entries 4-6)). This method is operationally simple and may be practically useful. 
Figure 7. Plots of (a) $\ln \left([\mathrm{M}]_{0} /[\mathrm{M}]\right) v s$. $t$ and (b) $M_{\mathrm{n}}$ and $M_{\mathrm{w}} / M_{\mathrm{n}} v s$. conversion for the $\mathrm{MMA} / \mathrm{I}_{2} / \mathrm{V} 70 / \mathrm{TiBP}$ systems $\left(60{ }^{\circ} \mathrm{C}\right)$ (entries $1-3$ in Table 3$):[\mathrm{MMA}]_{0}=8 \mathrm{M}$. The polymerization was carried out in bulk (for targeted DP $=130$ and 270 ) and in $25 \mathrm{wt} \%$ toluene (for targeted DP $=530$ ). The concentrations of $\mathrm{I}_{2}, \mathrm{~V} 70$ and TiBP and the symbols are as indicated in the figure. V65 $(5 \mathrm{mM})$ was added for targeted DP $=530$.
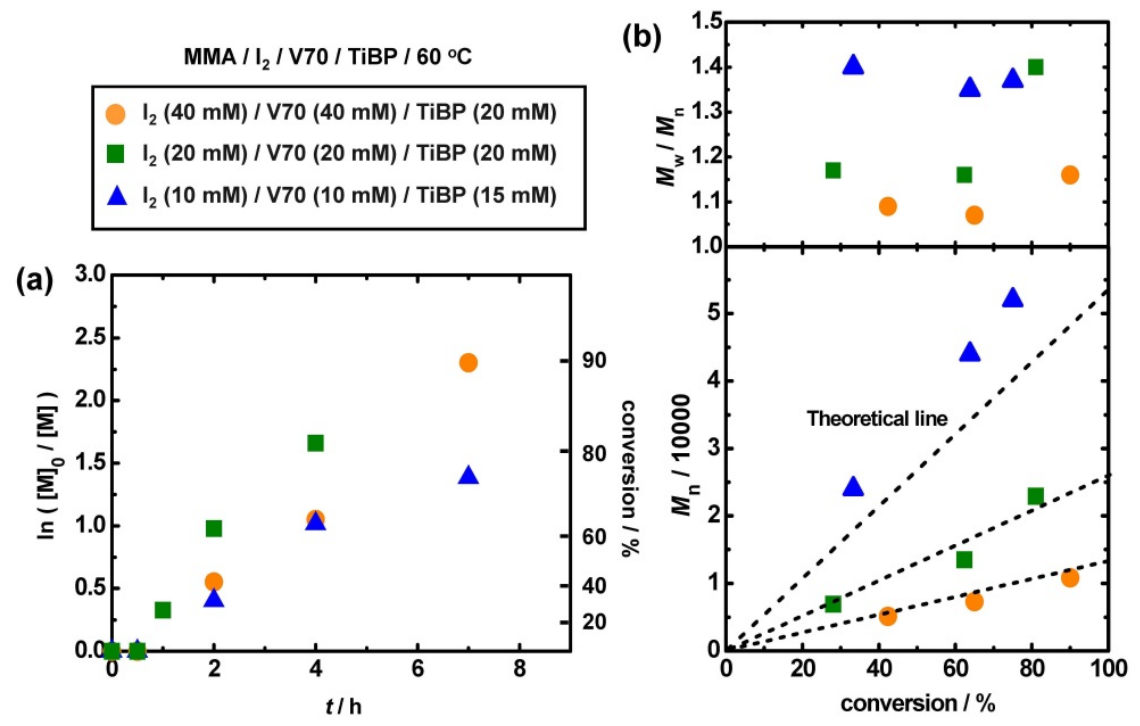

Table 3. Polymerizations of MMA and St with in Situ Generated Alkyl Iodine.

\begin{tabular}{ccccccccccc}
\hline Entry & Monomer & $\begin{array}{c}\text { Target } \\
\text { DP }\end{array}$ & Catalyst & $\begin{array}{c}\left.[\mathbf{m o n o m e r}]_{\mathbf{0}} / \mathbf{I}_{2}\right]_{\mathbf{0}} \\
{[\mathbf{V 7 0}]_{\mathbf{0}} /[\mathbf{c a t a l y s t}]_{\mathbf{0}}} \\
\mathbf{( m M )}\end{array}$ & Solvent & $\begin{array}{c}\boldsymbol{T} \\
\left({ }^{\circ} \mathbf{C}\right)\end{array}$ & $\begin{array}{c}\boldsymbol{t} \\
(\mathbf{h})\end{array}$ & $\begin{array}{c}\text { Conv } \\
\mathbf{( \% )}\end{array}$ & $\boldsymbol{M}_{\mathbf{n}}\left(\boldsymbol{M}_{\mathbf{n}, \text { theo }}\right)$ & PDI \\
\hline 1 & MMA & 130 & TiBP & $8000 / 40 / 40 / 20$ & Bulk & 60 & 7 & 95 & $11,000(12,000)$ & 1.16 \\
2 & MMA & 270 & TiBP & $8000 / 20 / 20 / 20$ & Bulk & 60 & 4 & 81 & $23,000(22,000)$ & 1.40 \\
3 & MMA & 530 & TiBP & $8000 / 10 / 10 / 15^{\text {a }}$ & Toluene ${ }^{b}$ & 60 & 23 & 74 & $52,000(40,000)$ & 1.36 \\
4 & St & 100 & TiBP & $8000 / 40 / 55 / 20$ & Bulk & 80 & 7 & 74 & $11,000(7,700)$ & 1.4 \\
5 & St & 100 & TMG & $8000 / 40 / 50 / 40$ & Bulk & 80 & 10 & 100 & $12,000(11,000)$ & 1.4 \\
6 & St & 100 & t-Bu-P ${ }_{4}$ & $8000 / 40 / 60 / 5$ & Bulk & 80 & 9 & 81 & $11,000(8,500)$ & 1.38 \\
\hline
\end{tabular}

${ }^{a}$ Addition of V65 (5 mM). ${ }^{b}$ Diluted in $25 \mathrm{wt} \%$ toluene (solution polymerization).

\section{Conclusions}

R-I reacted with organic superbases to reversibly generate $\mathrm{R}^{\circ}$. With this reaction, the organic superbases were successfully employed as highly reactive catalysts for RCMP. The catalysts enabled the synthesis of low-polydispersity polymers (up to $M_{\mathrm{n}}=52,000$ ) through high conversions (e.g., 80\%) in reasonably short times (e.g., 3-12 h) at mild temperatures $\left(60-80{ }^{\circ} \mathrm{C}\right)$ for MMA, St and three functional methacrylates. The described catalyst system was free from metals. The facile operation, high polymerization rate and good monomer versatility may be beneficial in a variety of applications.

\section{Acknowledgments}

This work was partly supported by Grants-in-Aid for Scientific Research from the Japan Society of the Promotion of Science (JSPS) and the Japan Science and Technology Agency (JST). Ethyl 
2-iodoisobutyrate (EMA-I) was provided through the courtesy of Godo Shigen Sangyo Co., LTD, Chiba, Japan. NMR (nuclear magnetic resonance) spectra (Figure 2) were acquired with the NMR spectrometer in the Joint Usage/Research Center (JURC) at Institute for Chemical Research, Kyoto University.

\section{Conflicts of Interest}

The authors declare no conflict of interest.

\section{References}

1. Mukherjee, S.; Yang, J.W.; Hoffmann, S.; List, B. Asymmetric Enamine Catalysis. Chem. Rev. 2007, 107, 5471-5569.

2. Hegedus, L.S. Organocatalysts in Organic Synthesis. J. Am. Chem. Soc. 2009, 131, 17995-17997.

3. Zhong, C.; Shi, X. When Organocatalysis Meets Transition-Metal Catalysis. Eur. J. Org. Chem. 2010, 2010, 2999-3025.

4. Grasa, G.A.; Singh, R.; Nolan, S.P. Transesterification/Acylation Reactions Catalyzed by Molecular Catalysts. Synthesis 2004, 2004, 971-985.

5. Sohtome, Y.; Hashimoto, Y.; Nagasawa, K. Guanidine-Thiourea Bifunctional Organocatalyst for the Asymmetric Henry (Nitroaldol) Reaction. Adv. Synth. Catal. 2005, 347, 1643-1648.

6. Ishikawa, T.; Kumamoto, T. Guanidines in Organic Synthesis. Synthesis 2006, 2006, 737-752.

7. Melchiorre, P.; Marigo, M.; Carlone, A.; Bartoli, G. Asymmetric Aminocatalysis - Gold Rush in Organic Chemistry. Angew. Chem. Int. Ed. 2008, 47, 6138-6171.

8. Lohmeijer, B.G.G.; Pratt, R.C.; Leibfarth, F.; Logan, J.W.; Long, D.A.; Dove, A.P.; Nederberg, F.; Choi, J.; Wade, C.; Waymouth, R.M.; Hedrick J.L. Guanidine and Amidine Organocatalysts for Ring-Opening Polymerization of Cyclic Esters. Macromolecules 2006, 39, 8574-8583.

9. Kakuchi, T.; Chen, Y.; Kitakado, J.; Mori, K.; Fuchise, K.; Satoh, T. Organic Superbase as an Efficient Catalyst for Group Transfer Polymerization of Methyl Methacrylate. Macromolecules 2011, 44, 4641-4647.

10. Tsarevsky, N.V.; Sumerlin, B.S. Fundamentals of Controlled/Living Radical Polymerization, 1st ed.; Royal Society of Chemistry: London, UK, 2013.

11. Matyjaszewski, K.; Möller, M. Polymer Science: A Comprehensive Reference, 1st ed.; Elsevier: Amsterdam, the Netherlands, 2012.

12. Moad, G.; Solomon, D.H. The Chemistry of Radical Polymerization, 2nd ed.; Elsevier: Amsterdam, the Netherlands, 2006.

13. Nicolas, J.; Guillaneuf, Y.; Lefay, C.; Bertin, D.; Gigmes, D.; Charleux, B. Nitroxide-mediated polymerization. Prog. Polym. Sci. 2013, 38, 63-235.

14. Matyjaszewski, K. Atom transfer radical polymerization (ATRP): Current status and future perspectives. Macromolecules 2012, 45, 4015-4039.

15. Ouchi, M.; Terashima, T.; Sawamoto, M. Transition metal-catalyzed living radical polymerization: Toward perfection in catalysis and precision polymer synthesis. Chem. Rev. 2009, 109, 4963-5050.

16. Lena, F.; Matyjaszewski, K. Transition metal catalysts for controlled radical polymerization. Prog. Polym. Sci., 2010, 35, 959-1021. 
17. Moad, G.; Rizzardo, E.; Thang, S.H. Living radical polymerization by the RAFT process-A second update. Aust. J. Chem. 2009, 62, 1402-1472.

18. Keddie, D.J.; Moad, G.; Rizzado, E.; Thang, S.H. RAFT agent design and synthesis. Macromolecules 2012, 45, 5321-5342.

19. David, G.; Boyer, C.; Tonnar, J.; Ameduri, B.; Lacroix-Desmazes, P.; Boutevin, B. Use of iodocompounds in radical polymerization. Chem. Rev. 2006, 106, 3936-3962.

20. Yamago, S. Precision polymer synthesis by degenerative transfer controlled/living radical polymerization using organotellurium, organostibine and organobismuthine chain-transfer agents. Chem. Rev. 2009, 109, 5051-5068.

21. Fukuda, T. Fundamental kinetic aspects of living radical polymerization and the use of gel permeation chromatography to shed light on them. J. Polym. Sci. A Polym. Chem. 2004, 42, 4743-4755.

22. Fischer, H. The persistent radical effect: A principle for selective radical reactions and living radical polymerizations. Chem. Rev. 2001, 101, 3581-3618.

23. Goto, A.; Fukuda, T. Kinetics of living radical polymerization. Prog. Polym. Sci. 2004, 29, 329-385.

24. Fukuda, T.; Goto, A. Controlled and Living Radical Polymerization-Principles and Fundamentals. In Polymer Science: A Comprehensive Reference, 1st ed.; Matyjaszewski, K., Möller, M., Eds.; Elsevier: Amsterdam, the Netherlands, 2012; pp. 120-157.

25. Goto, A.; Zushi, H.; Hirai, N.; Wakada, T.; Tsujii, Y.; Fukuda, T. Living radical polymerizations with germanium, tin and phosphorus catalysts-Reversible chain transfer catalyzed polymerizations (RTCPs). J. Am. Chem. Soc. 2007, 129, 13347-13354.

26. Goto, A.; Hirai, N.; Wakada, T.; Nagasawa, K.; Tsujii, Y.; Fukuda, T. Living radical polymerization with nitrogen catalyst: Reversible chain transfer catalyzed polymerization with $\mathrm{N}$-iodosuccinimide. Macromolecules 2008, 41, 6261-6264.

27. Goto, A.; Hirai, N.; Nagasawa, K.; Tsujii, Y.; Fukuda, T.; Kaji, H. Phenols and carbon compounds as efficient organic catalysts for reversible chain transfer catalyzed living radical polymerization (RTCP). Macromolecules 2010, 43, 7971-7978.

28. Vana, P.; Goto, A. Kinetic simulations of reversible chain transfer catalyzed polymerization (RTCP): Guidelines to optimum molecular weight control. Macromol. Theory Simul. 2010, 19, 24-35.

29. Yorizane, M.; Nagasuga, T.; Kitayama, Y.; Tanaka, A.; Minami, H.; Goto, A.; Fukuda, T.; Okubo, M. Reversible chain transfer catalyzed polymerization (RTCP) of methyl methacrylate with nitrogen catalyst in an aqueous microsuspension system. Macromolecules 2010, 43, 8703-8705.

30. Goto, A.; Tsujii, Y.; Fukuda, T. Reversible chain transfer catalyzed polymerization (RTCP): A new class of living radical polymerization. Polymer 2008, 49, 5177-5185.

31. Goto, A.; Tsujii, Y.; Kaji, H. Living Radical Polymerizations with Organic Catalysts. In Fundamentals of Controlled/Living Radical Polymerization, 1st ed.; Tsarevsky, N.V., Sumerlin, B.S., Eds.; Royal Society of Chemistry: London, UK, 2013; pp. 250-286.

32. Goto, A.; Suzuki, T.; Ohfuji, H.; Tanishima, M.; Fukuda, T.; Tsujii, Y.; Kaji, H. Reversible Complexation Mediated Living Radical Polymerization (RCMP) using organic catalysts. Macromolecules 2011, 44, 8709-8715.

33. Goto, A.; Tsujii, Y.; Kaji, H. Reversible Complexation Mediated Polymerization (RCMP) of Methyl Methacrylate. ACS Symp. Ser. 2012, 1100, 305-315. 
34. Ohtsuki, A.; Goto, A.; Kaji, H. Visible-Light-Induced reversible complexation mediated living radical polymerization of methacrylates with organic catalysts. Macromolecules 2013, 46, 96-102.

35. Goto, A.; Ohtsuki A.; Ohfuji, H.; Tanishima, M.; Kaji, H. Reversible generation of a carbon-centered radical from alkyl iodide using organic salts and their application as organic catalysts in living radical polymerization. J. Am. Chem. Soc. 2013, 135, 11131-11139.

36. Moad, G.; Rizzardo, E. Alkoxyamine-Initiated Living Radical Polymerization: Factors Affecting Alkoxyamine Homolysis Rate. Macromolecules 1995, 28, 8722-8728.

37. Goto, A.; Fukuda, T. Determination of the activation rate constants of alkyl halide initiators for atom transfer radical polymerization. Macromol. Rapid Commun. 1999, 20, 633-636.

38. Schulte, T.; Studer, A. New Seven- and Eight-Membered Cyclic Alkoxyamines for the Living Free Radical Polymerization. Macromolecules 2003, 36, 3078-3084.

39. Ishikawa, T. Superbases for Organic Synthesis: Guanidines, Amidines, Phosphazenes and Related Organocatalysts; John Wiley \& Sons: London, UK, 2009.

40. Lacroix-Desmazes, P.; Severac, R.; Boutevin, B. Reverse iodine transfer polymerization of methyl acrylate and n-butyl acrylate. Macromolecules 2005, 38, 6299-6309.

41. Tonnar, P.; Lacroix-Desmazes, P. Use of sodium iodide as the precursor to the control agent in ab initio emulsion polymerization. Angew. Chem. Int. Ed. 2008, 47, 1294-1297.

(C) 2014 by the authors; licensee MDPI, Basel, Switzerland. This article is an open access article distributed under the terms and conditions of the Creative Commons Attribution license (http://creativecommons.org/licenses/by/3.0/). 